ISSN: 2638-6003

\title{
The Terrible Triad Miracle
}

\author{
Vivek Nadipalli and Nikoletta Carayannopoulos* \\ Clinical Associate Professor at the University of Houston School of Medicine, USA
}

*Corresponding author: Nikoletta Carayannopoulos, Department West Houston Orthopedics, Address: 12606 W, W. Medical Center Blvd Suite 350, Houston, TX 77082, USA

\section{Abstract}

Introduction: The terrible triad injury of the elbow is a fracture-dislocation injury consisting of a radial head fracture, coronoid fracture and dislocation of the elbow. This injury is relatively uncommon and despite surgical management these injuries often go on to develop various complications.

Case Presentation: Presented is a terrible triad elbow injury of the left elbow in an 18-year-old male. The patient underwent open reduction internal fixation of the elbow and achieved exceptional outcomes. The joint was adequately stabilized through addressing the coronoid fracture and highly comminuted radial head. He was subsequently followed in clinic and placed on a conservative rehab approach.
\end{abstract}

Conclusion: Despite recent trends, the joint was aggressively stabilized, and the patient was placed through conservative rehab. In this case, the patient was able to achieve satisfactory outcomes in a short period of time.

Keywords: Elbow; Fracture Dislocation; Terrible Triad Injury

\section{Introduction}

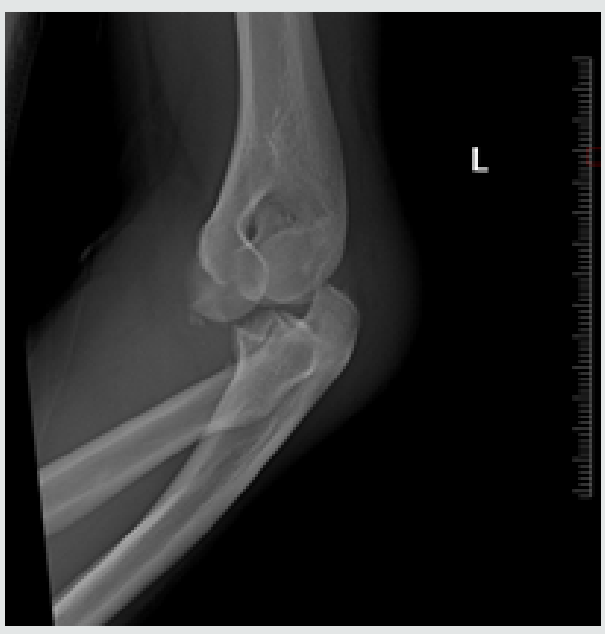

Figure 1: Lateral view Xray of left elbow pre-reduction.

The terrible triad injury of the elbow is a fracture-dislocation injury consisting of a radial head fracture, coronoid fracture and dislocation of the elbow [1-5]. It was first described by Hotchkiss in 1996 and named so due to the poor outcomes experienced by these patients [1]. Despite surgical management these injuries often go on to develop various complications: recurrent instability, stiffness, posttraumatic arthritis, heterotopic ossification and fixation failure. This injury is relatively uncommon and studies attempting to analyze outcomes often have a low number of subjects [1]. We present a case of a terrible triad injury with exceptional range of motion outcomes within a short time frame (Figure 1 and 2).

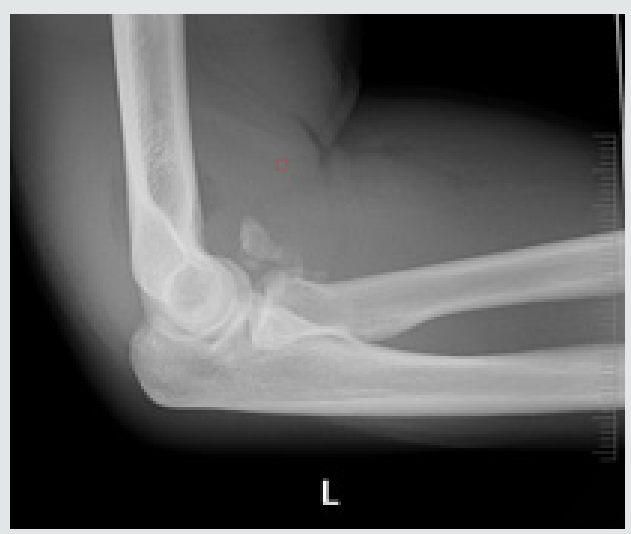

Figure 2: Lateral view Xray of left elbow post-reduction. 


\section{Case Presentation}

A healthy 18-year-old male presented to West Houston Orthopedics for evaluation of left elbow pain. He fell two days ago while skateboarding and was evaluated at an outside emergency department. He was diagnosed with a left elbow fracturedislocation treated at the time with reduction and splinting. At his initial orthopedic clinic visit, evaluation of radiographs revealed a reduced left elbow fracture-dislocation with a displaced, comminuted fracture of the coronoid and associated displaced, comminuted fracture of the radial head. CT scan of the elbow revealed displaced and extensively comminuted intra-articular fracture of the radial head involving at least $40-50 \%$ of the articular surface. The coronoid process was extensively comminuted with sublime tubercle involvement and likely the distal insertion of the ulnar collateral ligament (Figure 3). Mildly displaced fractures along the posterior capitellum were also identified. The patient was treated with open reduction internal fixation (ORIF) left radial head, ORIF coronoid process and lateral collateral ligament reconstruction 5 days after presentation to clinic. A single extensor digitorum communis splitting approach was used to gain access to the joint. The exposed radial head was in one large piece and several smaller pieces which included 3 pieces amenable to fixation. The anterior capsule incision was then extended to access the coronoid fracture. Fragmented cartilage pieces from the ulnohumeral and radiocapitellar joint were removed from the joint. An attempt to fixate a larger coronoid fragment was made; however, the piece further fragmented, and fixation was no longer possible.
A $1.8 \mathrm{~mm}$ suture anchor was then placed for suture fixation of the anterior capsule following radial head fixation. The larger radial head fragments were reduced and fixated using two mini headless screws placed with compression.

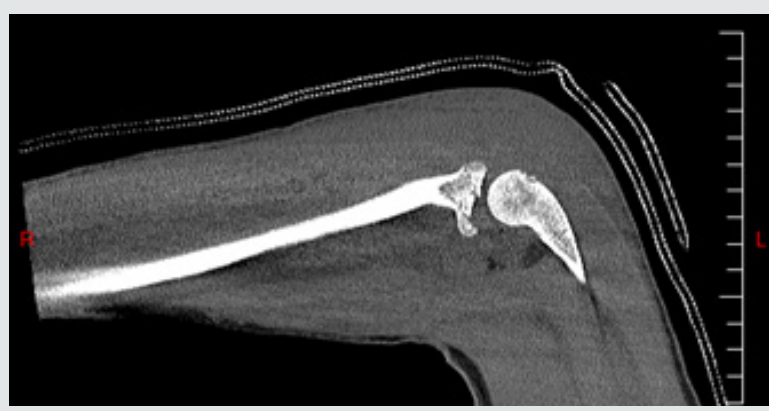

Figure 3: CT sagittal view of left elbow.

The remaining coronoid fragments were removed from the joint and the Fiber Wire was used to fixate the anterior capsule to the remaining coronoid. Fluoroscopy confirmed reduction of the fracture with concentric joint reduction with the elbow flexed and supinated. The LCL was repaired using 0 Vicryl. The annular ligament was similarly repaired along the radial head and neck. Hard copy radiographs were obtained after closure and confirmed reduction of the fracture with concentric elbow joint reduction and placement of hardware. Table 1 highlights the post-operative management of this patient along with his active range of motion at each visit.

Table 1: Post-operative Course.

\begin{tabular}{|c|c|c|c|c|c|c|c|}
\hline $\begin{array}{l}\text { Post-op } \\
\text { (Weeks) }\end{array}$ & $\begin{array}{l}\text { Presented to } \\
\text { Clinic In }\end{array}$ & Left Clinic In & $\begin{array}{c}\text { Plan for Coming } \\
\text { Weeks }\end{array}$ & Active Flexion & $\begin{array}{c}\text { Active } \\
\text { Extension }\end{array}$ & $\begin{array}{c}\text { Active } \\
\text { Pronation }\end{array}$ & $\begin{array}{c}\text { Active } \\
\text { Supination }\end{array}$ \\
\hline 2 & Posterior Splint & Posterior Splint & $\begin{array}{c}\text { Continue posterior } \\
\text { splint }\end{array}$ & $\mathrm{n} / \mathrm{a}$ & $\mathrm{n} / \mathrm{a}$ & $\mathrm{n} / \mathrm{a}$ & $\mathrm{n} / \mathrm{a}$ \\
\hline 4 & Posterior Splint & Posterior splint & $\begin{array}{c}\text { Order given for } \\
\text { hinged elbow brace }\end{array}$ & $100^{\circ}$ & $-85^{\circ}$ & $\mathrm{n} / \mathrm{a}$ & $\mathrm{n} / \mathrm{a}$ \\
\hline 6 & $\begin{array}{l}\text { Hinged elbow } \\
\text { brace locked } \\
\text { at minus } 60^{\circ} \\
\text { extension }\end{array}$ & $\begin{array}{l}\text { Hinged elbow } \\
\text { brace locked } \\
\text { at minus } 45^{\circ} \\
\text { extension }\end{array}$ & $\begin{array}{c}\text { Plan to extend } 10^{\circ} \\
\text { per week } \\
\text { Home exercises } \\
\text { initiated }\end{array}$ & $110^{\circ}$ & $-45^{\circ}$ & $\mathrm{n} / \mathrm{a}$ & $\mathrm{n} / \mathrm{a}$ \\
\hline 8 & $\begin{array}{c}\text { Hinged elbow } \\
\text { brace locked } \\
\text { at } 30^{\circ}\end{array}$ & $\begin{array}{l}\text { Unlocked hinged } \\
\text { elbow brace }\end{array}$ & $\begin{array}{c}\text { Wean off brace over } \\
1-2 \text { weeks } \\
\text { Begin formal } \\
\text { physical therapy }\end{array}$ & $130^{\circ}$ & $-30^{\circ}$ & $\mathrm{n} / \mathrm{a}$ & $\mathrm{n} / \mathrm{a}$ \\
\hline 12 & No brace & & & $0^{\circ}$ & $145^{\circ}$ & $70^{\circ}$ & $85^{\circ}$ \\
\hline
\end{tabular}

\section{Discussion}

The approach to surgical management of terrible triad injuries is still highly variable and outcomes are not well established. Giannicola et al. studied 78 elbows with complex elbow instability and found flexion, extension, pronation and supination at 3 months to be $131^{\circ}, 18^{\circ}, 76^{\circ}$ and $72^{\circ}$ respectively [2]. In a review done by Rodriguez-Martin et al. analyzing 137 elbow triad injuries from
5 studies following a protocol of fixation or replacement of radial head, fixation of coronoid fracture and repair of LCL complex, the weighted average flexion was $131.98^{\circ}$, extension was $-16.19^{\circ}$, forearm pronation was $76.35^{\circ}$ and forearm supination was $62.45^{\circ}$ [3]. In this case, the patient was able to achieve full range of motion of his elbow at just 3 months post-op without pain or signs of heterotopic ossification. Several factors may explain the favorable 
outcomes: the patient was young and healthy, the anterior capsule was stabilized to the coronoid, the radial head was fixed rather than replaced and the patient was progressed cautiously with close monitoring in a hinged elbow brace. The patient was also kept in a static splint for the first month of treatment without motion or PT.

There is increasing support for active elbow motion days after surgery in order to recruit the dynamic stabilizers of the elbow [3]. The idea that the elbow should never be immobilized is often viewed as dogma [4]. In the case of this patient, a more conservative rehab approach was utilized secondary to concern that formal physical therapy might stress the fixation too soon. The patient remained immobilized until 4 weeks post-operatively, at which point a hinged elbow brace prescription was given. The hinged brace was not fully unlocked until 8 weeks post-op. Additionally, formal physical therapy was delayed because of confidence that this patient would be compliant with home exercises. Given patient compliance and close monitoring, he was given a home exercise program six weeks post-operatively and a formal physical therapy referral at eight weeks post-operatively. While there is growing consensus that the coronoid fracture should be addressed due to its role in humeroulnar sagittal stability [1-5]; Chemama et al. recommend that type 1 coronoid fractures may be neglected. In this case we opted to reinsert the capsule via anchors for improved humeroulnar joint stability [5]. In addition to coronoid stabilization, we fixated the native radial head despite it being in greater than 3 pieces. An argument can be made that fixation of the radial head should be attempted prior to replacement. Watters et al found that arthroplasty had similar results to fixation; however, they further concluded that long-term studies need to be performed to identify the impact of late complications of arthroplasty such as loosening. In a young patient, the risk of arthroplasty revision in the long run may outweigh the risks carried by fixation [6] (Figure 4).

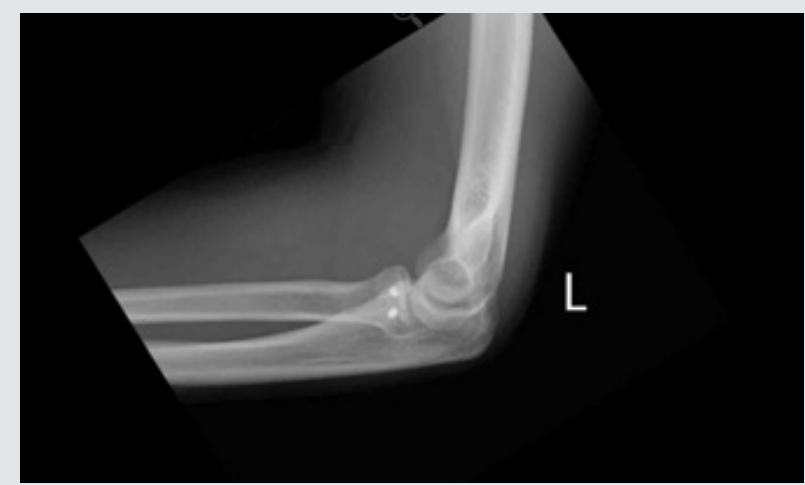

Figure 4: Lateral view Xray 16 weeks after ORIF

\section{Conclusion}

We report a case of a terrible triad injury in a young male who achieved an exceptional outcome despite early and extended immobilization of the joint. Despite recent trends to mobilize the joint early, the patient was able to achieve satisfactory outcomes in a short period of time. Furthermore, the joint was adequately stabilized through addressing the coronoid fracture and fixating a highly comminuted radial head.

\section{References}

1. Ring D, Jupiter JB, Zilberfarb J (2002) Posterior dislocation of the elbow with fractures of the radial head and coronoid. The Journal of bone and joint surgery. American volume 84(4): 547-551.

2. Giannicola G, Polimanti D, Bullitta G, Sacchetti FM, Cinotti G (2014) Critical time period for recovery of functional range of motion after surgical treatment of complex elbow instability: Prospective study on 76 patients. Injury 45(3): 540-545.

3. Rodriguez Martin J, Pretell Mazzini J, Andres Esteban EM, Larrainzar Garijo R (2011) Outcomes after terrible triads of the elbow treated with the current surgical protocols. A review. International orthopaedics 35(6): 851-860.

4. Duparc F, Merlet MC (2019) Prevention and management of early treatment failures in elbow injuries. Orthopaedics \& traumatology, surgery \& research: OTSR 105(1S): S75-S87.

5. ChemamaB,BonnevialleN,PeterO,MansatP,BonnevialleP(2010)Terrible triad injury of the elbow: How to improve outcomes? Orthopaedics \& traumatology, surgery \& research: OTSR 96(2): 147-154.

6. Watters TS, Garrigues GE, Ring D, Ruch DS (2014) Fixation versus replacement of radial head in terrible triad: Is there a difference in elbow stability and prognosis? Clinical orthopaedics and related research, 472(7): 2128-2135. 
(C) (1) This work is licensed under Creative

To Submit Your Article Click Here: Submit Article

DOI: $10.32474 /$ OSMOAJ.2020.04.000192

\begin{tabular}{l}
$\begin{array}{c}\text { Orthopedics and Sports Medicine } \\
\text { Open Access Journal } \\
\text { Assets of Publishing with us } \\
\text { - Global archiving of articles } \\
\text { - Immediate, unrestricted online access } \\
\text { - Rigorous Peer Review Process } \\
\text { - Authors Retain Copyrights }\end{array}$ \\
\hline Orthopedics And Sports Medicine: \\
Open Access Jurnal
\end{tabular}

